Gut, 1973, 14, 54-58

\title{
Exocrine secretory responses of the pancreas to insulin and to a meat meal in dogs
}

\author{
S. GUPTA, J. B. ELDER, ${ }^{1}$ AND A. W. KAY \\ From the University Department of Surgery, Western Infirmary, Glasgow
}

SUMMARY Studies in five dogs with chronic pancreatic and gastric fistulae have shown that insulininduced vagal stimulation of the pancreas (gastric fistula open) resulted in protein and bicarbonate outputs very much smaller than those obtained with a $400-\mathrm{g}$ meat meal. However, when the insulinactivated gastric acid secretion was allowed access to the duodenum (gastric fistula closed) peak outputs of both bicarbonate and protein were observed which were closely similar to the response to the meal. These findings suggest that insulin-induced hypoglycaemia results in stimulation of the pancreas within the physiological range when gastric acid is allowed access to the duodenum with consequent release of secretin.

Stimulation of the vagus nerves has been shown to cause a small increase in the volume of exocrine secretion of the pancreas and a considerable increase in output of enzymes (Lobassov, 1910). Cephalic, gastric, and intestinal phases of pancreatic secretion have now been identified (Grossman, 1971), but little is known of the relationships of these phases to the response to a meal. The aim of this paper is to compare the exocrine secretory response of the pancreas during the cephalic phase of pancreatic secretion as induced by insulin hypoglycaemia with that obtained by a meat meal of $400 \mathrm{~g}$ in dogs.

\section{Methods}

Observations were made on five mongrel dogs weighing between 15 and $22 \mathrm{~kg}$. In each animal the stomach was drained at its most dependent part by means of a Thomas cannula and a chronic pancreatic fistula was formed by the technique described by Preshaw and Grossman (1965). Between experiments in this model pancreatic juice enters the duodenum and the animals do not develop steatorrhoea.

At least six weeks were allowed to elapse after operation before beginning observations. Following an 18-hour fast the animals were placed in slings and both duodenal and gastric fistulae were opened, allowed to drain, and then washed out with $100 \mathrm{ml}$ of $0.9 \%$ sodium chloride. Pancreatic juice was

${ }^{1}$ Correspondence to: J. B. Elder, University Department of Surgery, Manchester Royal Infirmary, Oxford Road, Manchester M13 9WL. Received for publication 4 July 1972. collected continuously by gravity drainage and every 30 minutes the volume was measured in millilitres. Total protein concentration $(\mathrm{mg} / \mathrm{ml})$ was estimated by Lowry's method (Lowry, Rosebrough, Farr, and Randall, 1951), and protein output $(\mathrm{mg} / 30$ min) was calculated from the product of the volume multiplied by concentration.

Bicarbonate concentration in each 30-minute sample was measured by the addition of $1.0 \mathrm{ml}$ of $0.1 \mathrm{NHCl}$ to $0.5 \mathrm{ml}$ of the sample, heating the mixture to boiling for five seconds, and then back titrating the residual acid with $0 \cdot 1 \mathrm{~N} \mathrm{NaOH}$ using

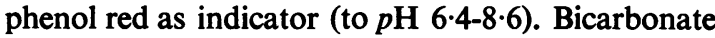
output (m-equiv/30 min) was expressed as the product of volume multiplied by concentration.

After two basal collections the exocrine secretory response of the pancreas to insulin $(0.2$ units $/ \mathrm{kg}$ iv) was measured for four hours, first with the gastric fistula open (allowing gastric contents to drain freely and thereby preventing access of acid to the duodenum and consequent release of endogenous secretin), and secondly with the gastric fistula closed (allowing acid access to the duodenum with release of secretin). On a separate day, the exocrine response of the pancreas to a $400 \mathrm{~g}$ meat meal was measured. On this occasion the gastric fistula remained closed. Throughout the course of the study the dogs were fed on a normal diet of meat and biscuits and maintained their weight. One dog developed an abscess close to the duodenal cannula and this required incision and drainage. Observations were not made on this animal at this time. 


\section{Results}

Figure 1 shows the effect of insulin $(0.2$ units $/ \mathrm{kg})$ on the bicarbonate output of the pancreas. Peak bicarbonate output occurred 60 minutes after injection of insulin. With the gastric fistula closed and acid entering the duodenum releasing endogenous secretin, bicarbonate output, as expected, was significantly greater than in experiments with the gastric fistula open $(P<0.001)$. In experiments with the gastric fistula open a significant increase in bicarbonate output after insulin was noted when compared with basal secretion $(\mathrm{P}<0.05)$. The $p \mathrm{H}$ of fluid obtained from the duodenum via the duodenal cannula was always greater than 6 when the gastric fistula was open during insulin-induced gastric acid secretion.

Figure 2 shows the effect of insulin on protein output from the pancreas. Peak output of protein

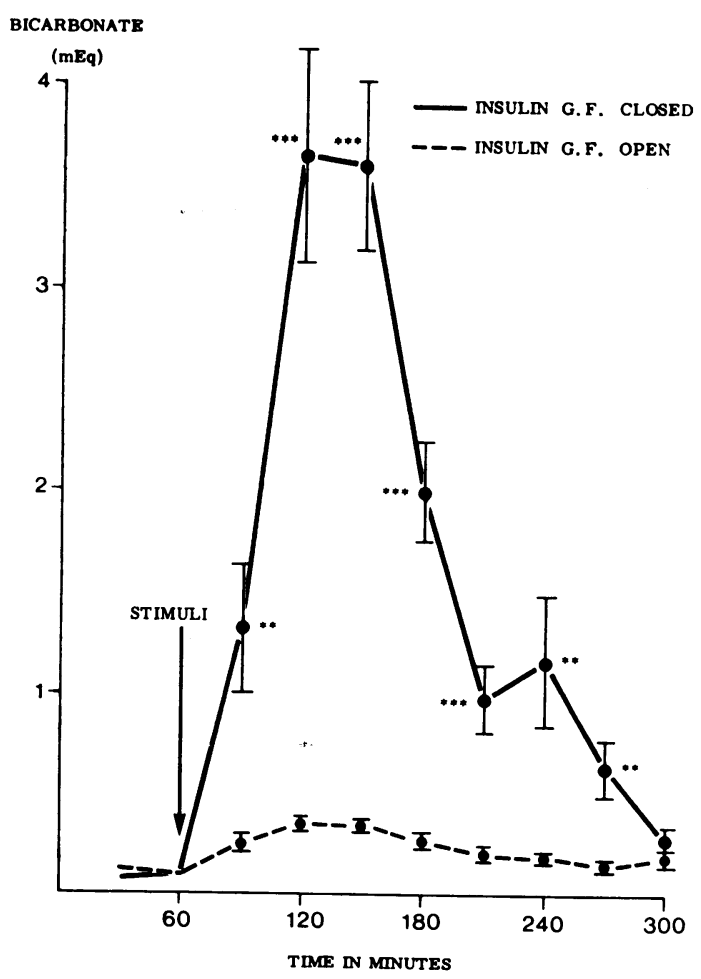

Fig. 1 Bicarbonate output response of canine pancreas to insulin hypoglycaemic stimulation $(0.2$ units $/ \mathrm{kg}$ iv). In this figure and subsequently through to Fig. 4, each point represents the mean $( \pm 1 S E M)$ of 15 experiments, three in each of five dogs. ${ }^{*} \mathrm{P}<0.05,{ }^{*} \mathrm{P}<0.01$, ${ }_{* * *} \mathrm{P}<0.001$. Bicarbonate outputs with the gastric fistula $(G F)$ closed were compared with those with it open.

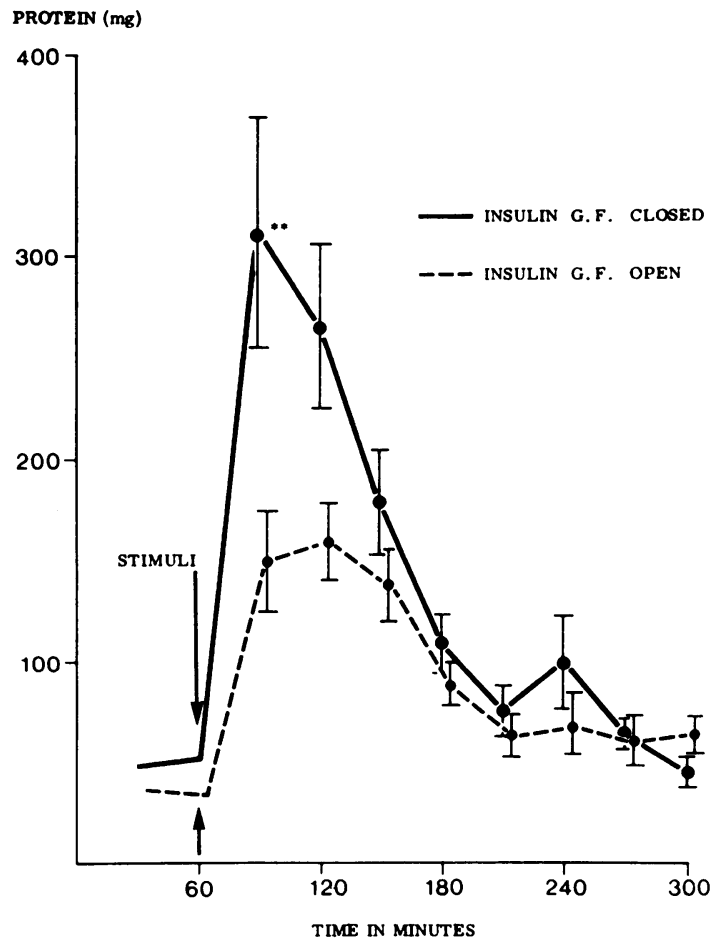

Fig. 2 Protein output from the pancreas to insulin was significantly greater with the gastric fistula closed compared to the gastric fistula open $(\mathrm{P}<0.01)$, and with the gastric fistula open marked elevation of protein output occurred in relation to basal levels.

with the gastric fistula closed occurred 30 minutes after the injection of insulin, and was significantly greater than that obtained in experiments with the gastric fistula open $(P<0.01)$. However, compared to the basal secretion in experiments with the gastric fistula open, a marked increase in output of protein was noted, suggesting vagal stimulation of the pancreas.

Figure 3 shows the comparison of bicarbonate outputs to insulin and to a $400 \mathrm{~g}$ meat meal with the gastric fistula closed. It can be seen that the initial increase, and indeed peak responses, to each stimulant were very similar, but that the response to insulin decreased markedly after two and a half hours and was back at almost basal levels by four hours, whereas the response to a $400 \mathrm{~g}$ meal decreased more slowly and was still markedly elevated above basal levels four hours after ingestion of the meal.

Figure 4 compares the protein output of the pancreas to insulin hypoglycaemia with that to a meat meal with the gastric fistula closed. It can be seen that the initial rapid rise in protein output was 


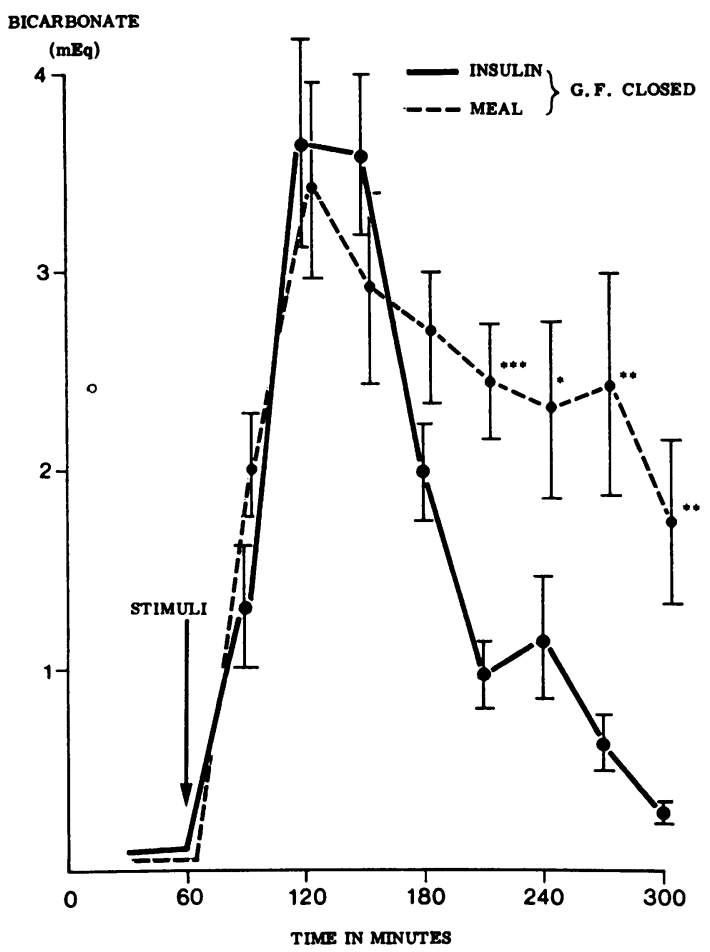

Fig. 3 Comparison of bicarbonate outputs after insulin $(0.2$ units $/ \mathrm{kg}$ iv) and after a meat meal $(400 \mathrm{~g})$ : peak outputs were similar but the levels after food were significantly greater throughout the latter half of the experiments.

similar for each stimulus, and peak output of protein was 30 minutes after either stimulant with no significant difference in the peak responses. However, as in the case of bicarbonate, protein output after insulin decreased sharply and was back again at basal levels within four hours of the insulin injection, whereas protein output decreased more gradually after a meal and remained significantly elevated at the conclusion of the experiment ( $\mathrm{P}<0.001)$.

Figure 5 shows the mean four-hour bicarbonate output (milli-equivalents) for each of the three groups of experiments performed. It can be seen that the four-hour bicarbonate response to insulin with the gastric fistula closed was significantly greater $(P<0.001)$ than the bicarbonate output with the gastric fistula open, and significantly less than that observed in response to a $400 \mathrm{~g}$ meat meal $(P<0.05)$.

In Fig. 6 it can be seen that the mean four-hour output of protein to insulin with the gastric fistula closed was significantly greater than that with the

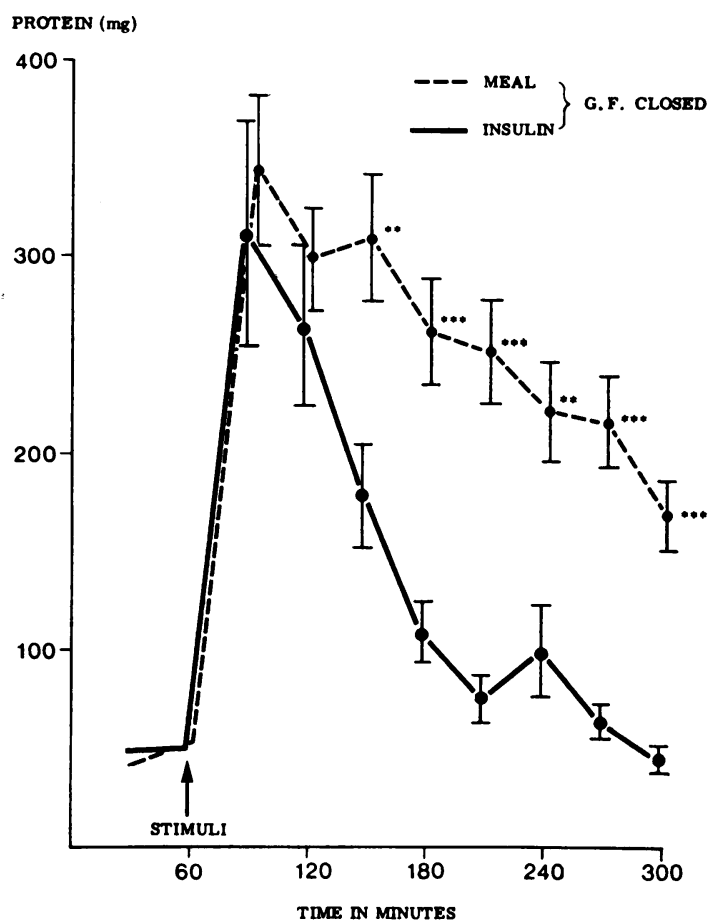

Fig. 4 Comparison of protein output after insulin and a meat meal $(400 \mathrm{~g})$.

gastric fistula open $(P<0.05)$ but was significantly less than that observed in response to a $400 \mathrm{~g}$ meat meal $(P<0.01)$.

\section{Discussion}

While it is possible that some degree of vagal denervation of the pancreas resulted from the construction of our experimental model, it is clear that some vagal innervation persisted, as was indicated by the sharp increase in protein output during insulin-induced hypoglycaemia with the gastric fistula open (Fig. 2).

If protein output to a $400 \mathrm{~g}$ meat meal is taken as a $100 \%$ response then the mean output of protein to insulin represented $41 \%$ (gastric fistula open) and $60 \%$ (gastric fistula closed) of the response to the meal. Similarly, if the mean four-hour output of bicarbonate to a $400 \mathrm{~g}$ meat meal under the conditions of the experiment is taken as $100 \%$, then the mean four-hour bicarbonate response to insulin represented 10\% (gastric fistula open) and $72 \%$ (gastric fistula closed) of the meal response. It is clear that when gastric acid is excluded from the duodenum the pancreatic outputs of protein and bicarbonate to vagal stimulation induced by insulin 


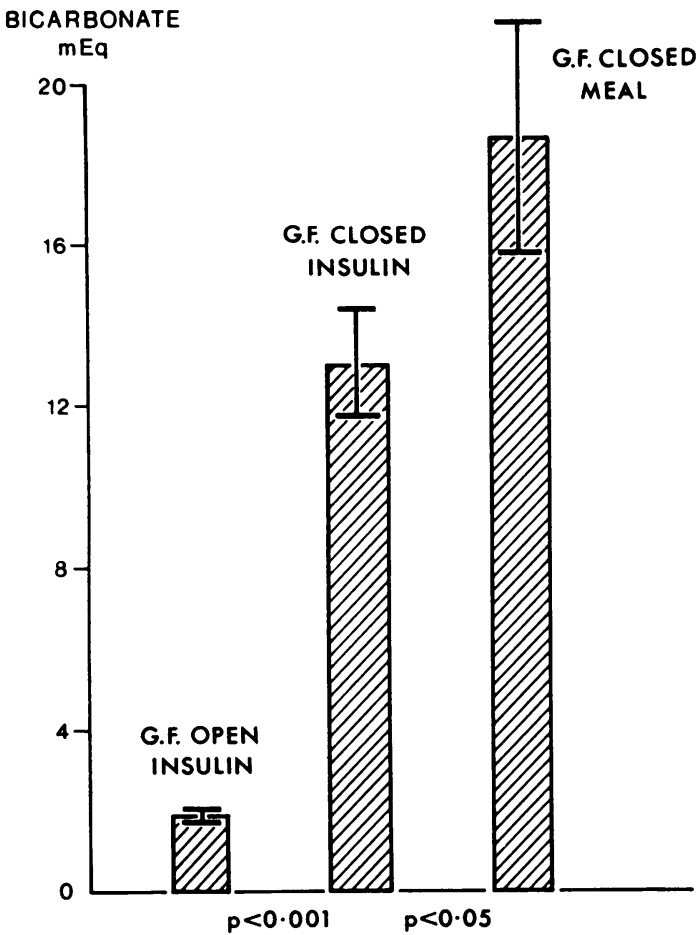

Fig. 5 Comparison of four-hour bicarbonate outputs from the pancreas to insulin (GF open and GF closed, 0.2 units $/ \mathrm{kg}$ iv) with the response to a meat meal. Each column represents the mean $( \pm 1$ SEM) of 15 experiments.

hypoglycaemia are considerably smaller than those occurring after a meat meal. However, in conjunction with endogenous secretin, ie, when the gastric fistula is closed, peak outputs of protein and bicarbonate were observed which did not differ significantly from those seen during the response to the meal. These findings suggest that insulininduced hypoglycaemia results in stimulation of the pancreas within the physiological range when gastric acid is allowed access to the duodenum.

We further speculate that the rapid fall of both protein and bicarbonate outputs in experiments with the gastric fistula closed during insulin hypoglycaemia is probably due to a diminished release of secretin consequent upon the decrease in acid entering the duodenum from the stomach.

In the experiments with insulin, pancreatic protein output increased when the gastric fistula was closed compared to those in which it was open, suggesting that the presence of acid in the duodenum augmented the vagally stimulated protein output, possibly by release of pancreozymin. The stimulatory effect of acid alone (Preshaw, Cook, and Grossman, 1966)

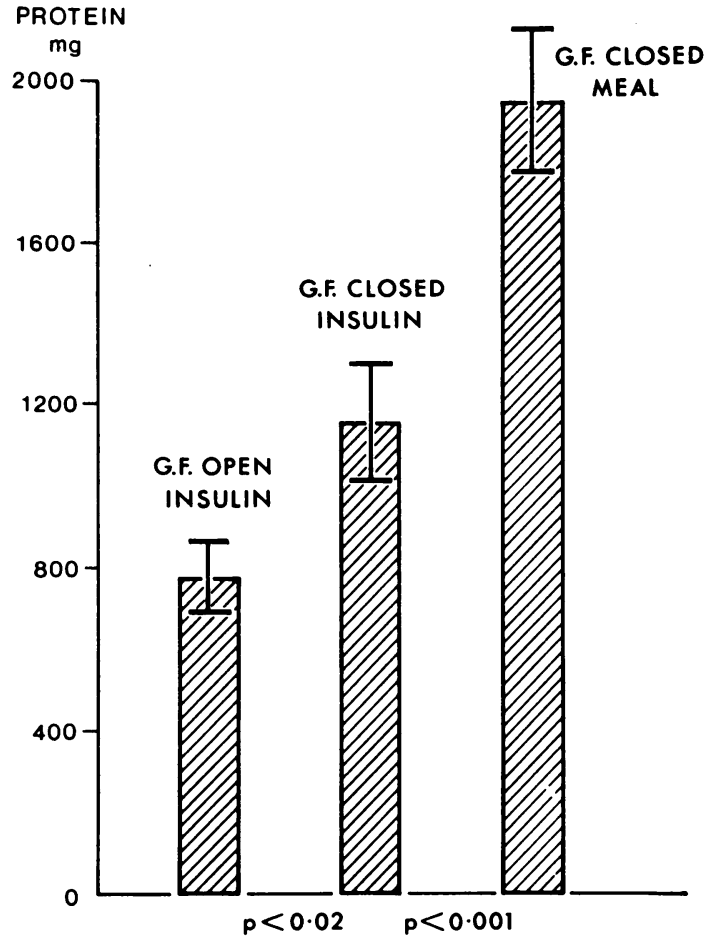

Fig. 6 Comparison of mean ( \pm 1 SEM) four-hour protein outputs from the pancreas.

and of acid plus insulin hypoglycaemia noted by others (Eisenberg and Orahood, 1971) on the pancreatic protein output is in keeping with such a mechanism.

Since both insulin and a meat meal are known to cause an increase in release of antral gastrin and of plasma gastrin concentration (Eisenberg, Emås, and Grossman, 1966; Ganguli and Elder, 1971; Ganguli, 1970), the effects of gastrin in these experiments must be considered. Since gastrin is known to cause an increase in protein output from the pancreas (Emås, Billings, and Grossman, 1968) it is likely that after both insulin and the $400 \mathrm{~g}$ meat meal, a part of the output of protein from the pancreas could be due to the stimulatory effects of antral gastrin directly on the pancreas. Direct evidence on this point from radioimmunoassay of plasma gastrin concentration during such experiments would be of great interest.

We wish to thank the laboratory and kennel staff of the Wellcome Surgical Research Institute, Garscube Estate, Bearsden, Glasgow, without whose skilled attention these studies could not have been performed. Our thanks are due also to the Western Regional Hospital Board for financial support, and 
to Medical Illustration, Western Infirmary, Glasgow, for the charts and photographs.

\section{References}

Eisenberg, M. M., Emås, G. S., and Grossman, M. I. (1966). Comparison of the effect of deoxy-D-glucose and insulin on gastric acid secretion in dogs. Surgery, 60, 111-117.

Eisenberg, M. M., and Orahood, R. C. (19i1). Vagal stimulation of the exocrine pancreas. Ann. Surg., 173, 462-466.

Emås, G. S., Billings, A., and Grossman, M. I. (1968). Effect of gastrin and pentagastrin on gastric and pancreatic secretion in dogs. Scand. J. Gastroent., 3, 234-240.

Ganguli, P. C. (1970). The effect of protein, carbohydrate, or fat on plasma gastrin concentration in human subjects. Gut, 11, 1061

Ganguli, P. C., and Elder, J. B. (1971). Effect of insulin hypo- glycaemia on plasma gastrin concentration and gastric acid secretion in normal subjects. Gut, 12, 861 .

Grossman, M. I. (1971). Control of pancreatic secretion. In The Exocrine Pancreas: Proceedings of a Symposium, June 1969, edited by I. T. Beck. Churchill, London.

Lobassov, I. O. (1910). The Work of the Digestive Glands, cited by I. P. Pavlov (2nd Engl. edition translated by W. H. Thompson) Griffin, London.

Lowry, O. H., Rosebrough, N. J., Farr, A. L., and Randall, R. J. (1951). Protein measurement with the Folin-phenol reagent. J. biol. Chem., 193, 265-275.

Preshaw, R. M., and Grossman, M. I. (1965). Stimulation of pancreatic secretion by extracts of the pyloric gland area of the stomach. Gastroenterology, 48, 36-44.

Preshaw, R. M., Cooke, A. R., and Grossman, M. I. (1966) Quantitative aspects of response of canine pancreas to duodenal acidification. Amer. J. Physiol., 210, 629-634.

\section{The December 1972 Issue}

\section{THE DECEMBER 1972 ISSUE CONTAINS THE FOLLOWING PAPERS}

Five cases of alpha chain disease WILLIAM F. DOE, K. HENRY, J. R. HOBBS, F. AVERY JONES, C. E. DENT, AND C. C. BOOTH

Intestinal immunoglobulins in children with coeliac disease E. SAVILAHTI

Dipeptide absorption in man M. D. HELLIER, C. D. HOLDSWORTH, I. MCCOLL, AND D. PERRETT

The size and histological appearances of mesenteric lymph nodes in Crohn's disease M. G. COOK

A comparison of results of excision and bypass for ileal Crohn's disease J. ALEXANDER-WILliams, J. F. FIELDING, AND W. T. COOKE

Plasmaphoresis and plasma exchange in the treatment of hyperlipaemia and xanthomatous neuropathy in patients with primary biliary cirrhosis L. A. TURNBERG, M. P. MAHONEY, M. H. GLEESON, C. B. FREEMAN, AND A. H. GOWENLOCK
Persistent ductus venosus without portal hypertension in a young alcoholic man P. BARJON, J.-L. LAMARQUE, H. MICHEL, J. FOURCADE, A. MIMRAN, AND J.-F. GINESTIE

Ultrastructural findings in idiopathic recurrent cholestasis D. HOPWOOD, A. E. READ, AND R. WILLIAMS

Validity of the correlation of gallstones and pancreatic pathology W. F. ERBER, E. LUBOWSKI, I. S. LEVIJ, AND D. BIRNBAUM

Progress report Carcinoembryonic antigen (CEA) PETER W. DYKES AND JOANNA KING

Progress report Cannulation of the papilla of Vater by endoscopy and retrograde cholangiopancreatography (ERCP) P. B. COTTON

\section{British Society for Digestive Endoscopy}

\section{Notes and activities}

Index to Volume 13

Contents of Volume 13

Copies are still available and may be obtained from the PUBLISHING MANAGER,

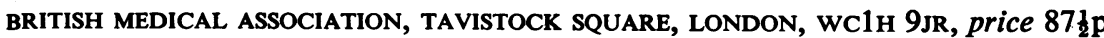

